\title{
LAND SUITABILITY ANALYSIS FOR THE PART OF PARAMBIKULAM ALIYAR COMMAND AREA, UDUMALPET TALUK USING REMOTE SENSING AND GIS TECHNIQUES
}

\author{
Mohana P.', Nethaji Mariappan V.E.', Manoharan N. ${ }^{3}$ \\ ${ }^{1,2}$ Scientists, Centre for Remote Sensing and Geoinformatics, Sathyabama University, Chennai, India \\ ${ }^{3}$ Sathyabama University, Chennai, India \\ Email: 'mohanaperumal@yahoo.com
}

\begin{abstract}
Land suitability analysis is a prerequisite for sustainable crop production. Incessant utilization of land and water resources is occurring in many parts of the world partly as a result of land management practices not being suitably matched to the suitability and capability of the land resources. To help address this problem for the part of Parambikulam Aliyar Command Area of Udumalpet taluk, there is dearth information on spatial distribution of present land use types. This paper describes a land suitability evaluation approach based on Remote sensing methodology and Geographical Information Systems (GIS). The Landsat ETM+ images was used to derive thematic maps like, soil type map, soil erosion, soil depth, soil texture and soil slope were derived apart from ETM data, based on the spectral reflectance and NDVI values, a land use and land cover map were prepared. A Land suitability classification map and aerial extent was prepared as per Soil survey and land use organization for sustainable development.
\end{abstract}

Keywords: Land Suitability, GIS, Remote Sensing

\section{INTRODUCTION}

Land suitability evaluation is the process of assessing the suitability of land for specified kinds of use. Land suitability classification is the process of appraisal and grouping of specific types of land in terms of their absolute or relative suitability for a specified kind of use. Land evaluation plays a major part in formulation of proposals, involving alternative forms of land use, and recognition of their main requirements, delineation of the different types of land present in the area, comparison and evaluation of each type of land for the different uses (Storie, 1954). Certain concepts and definitions are needed as a basis for the subsequent discussion. These concern the land itself, kinds of land use, land characteristics and qualities, and improvements made to land. Land comprises the physical environment like soil pH, soil texture, soil depth, including climate, relief, soils, hydrology (Tibbitts C.C. and Aubel James, 1980) and vegetation, to the extent that these influence potential for land use (Antaryami Mishra, 2007)

Remote sensing provides the information of landscapes synoptically, repetitively and objectively. It is an important source of spatial information such as land use and land cover which effectively illustrates the interaction between natural and human components in any region. The rapidly advancing technology, Geographic Information System (GIS) is a powerful tool for geoenvironmental analysis and appraisal of natural resources (Dipak Sarkar, 2006). It allows the user to integrate the data bases generated from various sources including RS on a single platform and analyze them efficiently in a spatial-temporal domain. GIS provides support in resource management and decision making.

The proposed study would make an attempt to assess the land evaluation in the semi-arid region of a Parambikulam Aliyar command area in Tamil Nadu using Remote Sensing and GIS.

\section{Objective:}

Primary aim of the study would be an appraisal of the land evaluation attributes of Parambikulam Aliyar command area for better utilization of the optimal available resources for sustainable agricultural development. This could be achieved by

- Generation of digital maps of physiography, slope, climate, erosion, soil type, soil depth, soil texture and land use and land cover etc.,

- Preparation of a crop inventory with respect to terrain and soil suitability of crops cultivated in the study region using RS and GIS

- To perform land suitability analysis and delineate suitable zones for crops under cultivation.

- Preparation of guidelines for the local farmers for achieving sustainable agriculture.

\section{Study area:}

Parambikulam Aliyar Project (PAP) command area is in Pollachi taluk of Coimbatore district, Tamil Nadu. The study area lies between $10^{\circ} 29^{\prime}$ to $11^{\circ} 6^{\prime}$ North Latitude and 
$77^{\circ} 8^{\prime}$ to $77^{\circ} 45^{\prime}$ East Longitude. This canal is of $30 \mathrm{~km}$ length (before extension), branches from the Parambikulam Main Canal (PMC) and the land under irrigation was about 7,700 before extension. The present command area is about 20,000 ha. Initially, five distributaries of this canal i.e., one in the head reach, one in the middle reach, one in the tail end of the old ayacut and two distributaries from the extended ayacut will be selected for the study. The study area is given in figure-1.

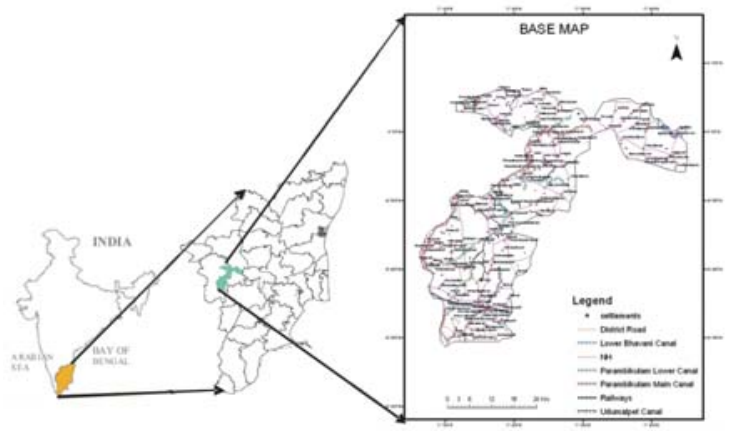

Fig. 1. Base Map of the Study Area

\section{Satellite Data:}

Base map of the study area were derived from Survey of India 1972 Toposheet of 1:50000 scale. LANDSAT $\mathrm{ETM}^{+}$data of path and row of $143-52,144-52,144-53$ of $1: 50000$ scale corresponding to the acquisition date of $15^{\text {th }}$ May 2001, 9th November $1999,14^{\text {th }}$ January 2001 was dow n loaded from the we bs it e http://glcfapp.umiacs.umd.edu. The satellite data LANDSAT ETM product has a total eight bands, seven bands with a spatial resolution of $30 \mathrm{~m}$ and eighth band of $15 \mathrm{~m}$ resolution.

The above geocoded data sets were mosaicked as per the standard procedure. The study area is subset from the mosaicked satellite data set. As the data of were of different dates. All the data sets were recalibrated to obtain homogeneity of the data. The bands of 2,3,4 are used for further analysis (Fig. 2). Associated inputs from the PWD (Public Works Department), IWS (Institute for Water Studies) and TNAU (Tamil Nadu Agricultural University) were incorporated for further analysis.

The command area boundary of Udumalpet canal as obtained from Tamil Nadu Public Works Department and the required data such as village maps, social economic data and other allied data were collected from VAO (Village Administrative Officer) of respective village. Fertility maps procured from Tamil Nadu Agricultural University (TNAU) is used for this study.

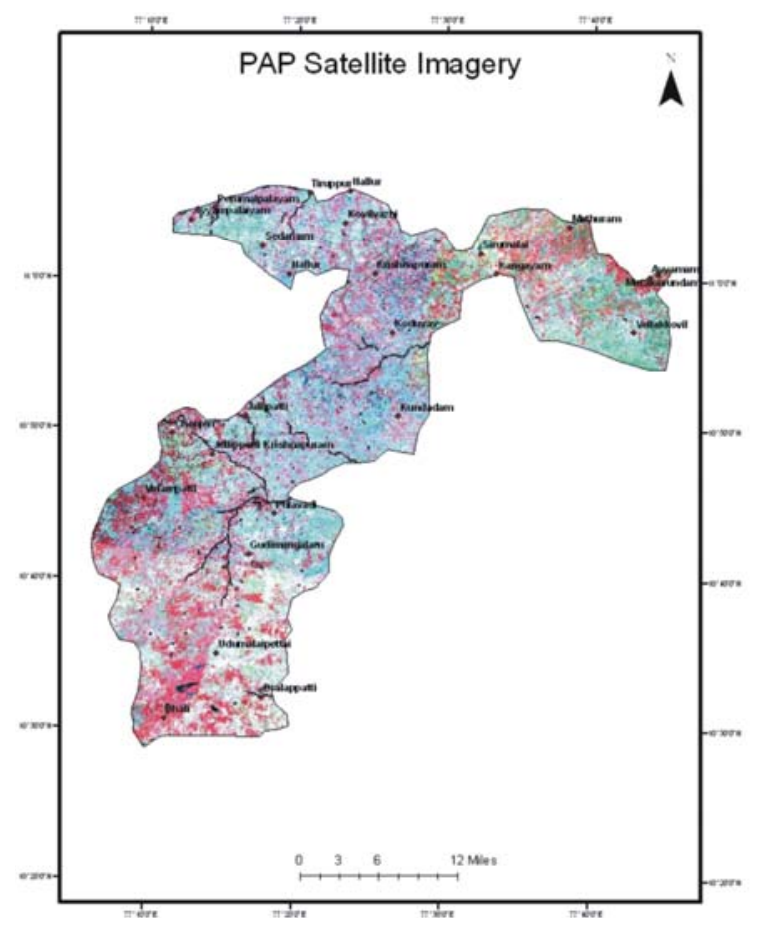

Fig. 2. Landsat $\mathrm{ETM}^{+}$Satellite Imagery

\section{METHODOLOGY}

The Survey of India toposheets of Scale 1:50,000 corresponding to the index map of 58e $4,58 \mathrm{e} 8,58 \mathrm{e} 12$ and 58e14 were used for base map preparation. Using Landsat satellite data, thematic layers such as soil map, soil erosion map, soil texture map and soil depth map were created in GIS database using ARC GIS 9.0 software.

Spatial soil maps at regional scale were obtained from soil survey and land use organization, Tamil Nadu. From these maps the following themes like wise soil type map, soil erosion, soil depth, soil texture and soil slope were derived. Later the field visit was undertaken to generate additional information for the above themes. Using Landsat satellite ETM data and based on the spectral reflectance and NDVI values, a land use and land cover map were prepared. This map is cross checked with the map of state land use board, TN. Agro climatic zonation map and climatic map of TNAU is used for this study. Pre field and post field ground truth verification for the thematic maps were cross checked, updated and final output was derived. Land suitability classification as per Soil survey and land use organization approach was employed for optimal utilization of natural resources and to derive crops suitability according to the land suitability analysis (Sys, 1976). 


\section{LAND SUITABILITY CLASSIFICATION}

Each plant species requires definite soil and land suitable conditions for its optimum growth. Although some plants may be found to grow under different soils and extreme agro-ecological conditions, yet not all plants can grow on the same soil and under the same environment (Mishra and Sahu, 1991), Since the availability of both water and plant nutrients is largely controlled by the physicochemical and micro environment of soils, the success and/or failure of any plant species, in a particular area, is largely determined by these factors. The deep rooted forest or orchard plantations respond differently to soil depth and soil texture (Mishra and Sahu,1991) than the shallow-rooted arable crops such as rice, wheat, green gram, black gram, pigeon-pea, groundnut, etc.,

Most of the plant species need well drained, moderately fine to medium texture soils, free of salinity and having optimum physical environment. Soil resource maps based on several parameters, can aid in predicting the behavior and suitability of soils for growing field crops, horticultural crops, forest species and other plantation crops once the suitability criteria is established (Sys and Verheye, 1975). Within limits, it may also find application in transfer of technology to other areas with comparable soil and land-site characteristics. Several systems of land evaluation have been proposed for use in different regions. Here, All India soil and land use survey organization classification was used to classify the land suitability (All India Soil Survey Manual, IARI, New Delhi. Pg: 49)

The land capability classes are divided into eight capability classes, capability sub-classes and capability units. The risks of land damage or limitation in use become progressively greater from class I to Class VIII.

Class I - Suitable land: Land on which sustained use for the defined purpose in the defined manner is expected to yield benefits that will justify required recurrent inputs without unacceptable risk to land resources. Class VIII Unsuitable land: Land is having characteristics which appear to preclude its sustained use for the defined purpose in the defined manner or which would create production, upkeep and/or conservation problems requiring a level of recurrent inputs unacceptable at the time of interpretation.

\section{RESULTS AND DISCUSSION}

From this study following themes soil type map, soil slope map, soil texture map, soil erosion map, soil fertility map and climatic map were generated. Soil type was broadly classified into three categories namely Vertisolsgenerally black in color with higher moisture holding capacity and swelling and shrinking character, Inceptisolsof loamy texture with medium to moderate water holding capacity, suitable for major crops cultivation and Alfisolsare generally dark red to red in color with less moisture holding capacity and more sandy nature, favourable for root crop cultivation, similarly soil depth classified into $1 / 250 \mathrm{~cm}, 50-100 \mathrm{~cm}$ and $1100 \mathrm{~cm}$, where as moderate to greater depth are favourable for economically viable crops. Soil slope categories into two classes namely $0-1 \%$ (nearly leveled) there are minimum chances of erosion.1$3 \%$ (slight slope) with slight erosion.

From this classification techniques class level I indicated the land area suitable for intensive cultivation to all climatically adopted crops (Abdul Hamid Hussein, 2006) and precaution of the area is no special difficulty in farming. Usual good farming practices to maintain soil fertility and conserve water. A total area of 57659.66 ha with percent area of 32.46 is under class I is shown in figure $3 \&$ table 1 .

Class level lle indicates good cultivable land with good soil on gentle slopes subject to water erosion or slight wind erosion on sandy soils. Land suitable for cultivation with little precautions, prefer conservation irrigation methods. A total area of 70396.7 ha with pare cent area of 39.63 is under class lle is shown in figure 3.

Class level Ils indicates moderately cultivable land, soil with minor soil problems such as clay or sandy texture, moderate depth or slight alkali. It's suitable for cultivation with selection of crops adapted to soil limitations. Special needs for treatment to offset soil limitations and to conserve irrigation water. A total area of 4012.14 ha with percent area of 2.26 is under class Ils is shown in figure 3 .

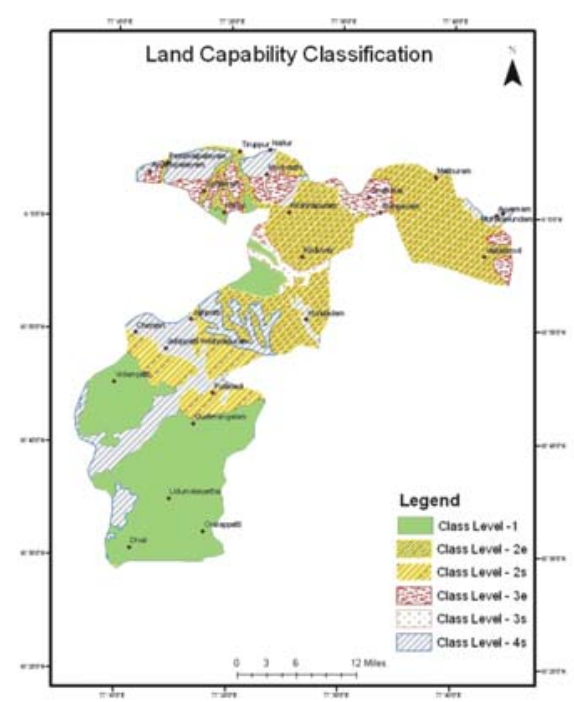

Fig. 3. Land Suitability Classification Map 
Class level Ille indicates moderately cultivable lands with good soil on moderate slopes subject to water erosion or sandy soil subject to wind erosion. Suitable for cultivation with precautions against permanent land damage. Special attention to erosion control and conservation irrigation. A total area of 12110.63 ha with percent area of 6.21 is under class lls is shown in figure 3 .

Class level IIls indicates soil with moderate problems due to moderate depth gravels or alkali. Suitable for cultivation with careful selection of crops adapted to soil limitations. Special needs to overcome soil limitations and conserve irrigation water. A total area of 2871.93 ha with percent area of 1.62 is under class Ils is shown in figure 3.

Class level IVs indicates fairly good land with limitations due to shallowness, gravel, stone or strong alkali. Suitable for occasional cultivation in rotation with hay or pasture. Special cares for vary intensive treatment to overcome soil limitations and careful selection of crops. A total area of 30588.12 ha with percent area of 17.22 is under class lls is shown in figure 3 .

Table 1. Parameters relating Land Suitability classification and its proportional area

\begin{tabular}{|l|l|l|ll|l|r|r|}
\hline S.No. & $\begin{array}{c}\text { Soil } \\
\text { Depth }\end{array}$ & \multicolumn{1}{|c|}{$\begin{array}{c}\text { Soil } \\
\text { Slope }\end{array}$} & Soil type & $\begin{array}{c}\text { Soil } \\
\text { Texture }\end{array}$ & $\begin{array}{c}\text { Land Suitability } \\
\text { Class }\end{array}$ & Areas in hec. & Percentage \\
\hline 1 & $1 / 200$ & $0-1 \%$ & Vertisols & Fine & Class Level -1 & $\mathbf{5 7 6 5 9 . 6 6}$ & 32.46 \\
2 & $50-100$ & $0-1 \%$ & Inceptisols & Fine & Class Level -2s & $\mathbf{7 0 3 9 6 . 7}$ & 39.63 \\
3 & $1 / 200$ & $1-3 \%$ & Inceptisols & Fine & Class Level -2e & $\mathbf{4 0 1 2 . 1 4}$ & 2.26 \\
4 & i 50 & $1-3 \%$ & Alfisols & Medium & Class Level -3e & $\mathbf{1 2 1 1 0 . 6 3}$ & 6.81 \\
5 & i 50 & $1-3 \%$ & Inceptisols & Coarse & Class Level -3s & $\mathbf{2 8 7 1 . 9 3}$ & 1.62 \\
6 & i 50 & $1-3 \%$ & Inceptisols & Fine & Class Level -4s & $\mathbf{3 0 5 8 8 . 1 2}$ & 17.22 \\
\hline & & & & & Total Area & 177639.18 & 100 \\
\hline
\end{tabular}

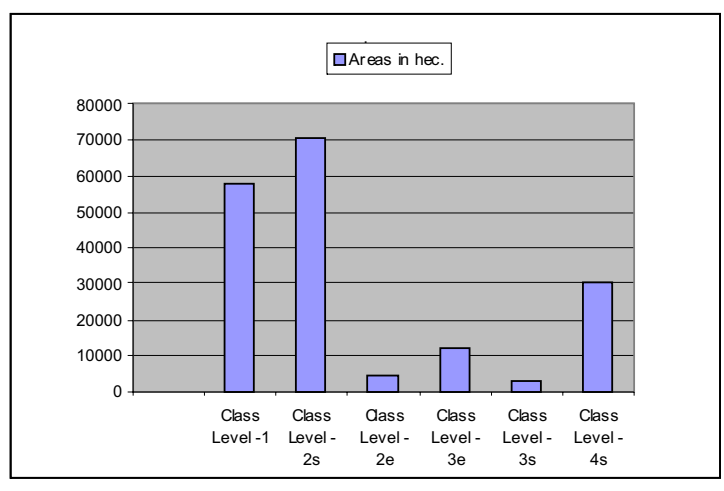

Fig. 4. Represent proportional contribution of area for each land suitability classes

\section{CONCLUSION}

The study clearly explains the methodology of Land suitability classification of the PAP and the proportionate area and per cent contribution for each category. Likewise category I is represented the area of $(57659.66$ hec.) $32.46 \%$ without any limitations might be due to availability at lower reaches of the river/distributaries that help farmers for improving land with higher cropping intensity. Second category of lle and Ils contribute (74408.84 hec) $41.89 \%$ with minor limitations that include either conservation strategies or salinity problem. In order to prevent such problem, organic mulching and flushing out salinity with alternative irrigation of before and after crop cultivation may help in improving the cropping intensity and optimize crop cultivation might hold well in terms improving productivity II category. An area of covers ( 15082.56 ha) with $8.74 \%$ comes under Category III. The limitations such as erosion and lower soil depth restrict the growth of most economic viable crops to be cultivated for this region and therefore erosion control measures and deep penetration crops like such as plantation crops and deep rooted crops are recommended. It will certainly improve the productivity of class III land. Category IV covers (30588.12 ha) $17.22 \%$ of area in the study area. In this area some pasture crops such as C01, Hybrid grass, Lemon grass, Guinea grass and forages are considered as alternative crops for the further development of the land (Nahry and Khashaba, 2006).

\section{REFERENCES}

[1] Sys, C., 1976. Land Evaluation. ITC, State Univ., Ghent, Belgium.

[2] Mishra, A. and Sahu,G.C.1991, Sisal-the strongest vegetable fiber crop. Orissa Review.

[3] Antaryami Mishra, 2007. Land Suitability classification for Different Crops, Orissa Review. 
[4] Anonymous, All India Soil Survey Manual, IARI, New Delhi. Pg: 49

[5] Dipak Sarkar, 2006. Soil Resource Appraisal towards Land use planning using Satellite remote sensing and GIS - a case study in Patloinala Micro-watershed. Journal of ISRS.

[6] Tibbitts C.C. and Aubel James, 1980, Groundwater resources investigation, Report prepared by US Geological Survey and Yemen Arab Republic.

[7] Abdul Hamid Hussein, 2006. Land Evaluation using RS \& GIS technology for the major crops in Amran valley, Yemen Republic. Doctorate Dissertation
[8] Nahry A.H and Khashaba H.E, 2006. Land suitability modeling of Natural Vegetation using Integrated Remote Sensing and GIS Techniques: A case study. Journal of Applied sciences 6(1):5156,2006 .

[9] Sys, C. and Verheye, W. 1975. Principles of land classification in arid and semi-arid regions. ITC, State Univ., Ghent, Belgium.

[10] Storie, R.E. 1954. Land classification as used in California. Fifth Int. Soil Conf. Leopoldville.

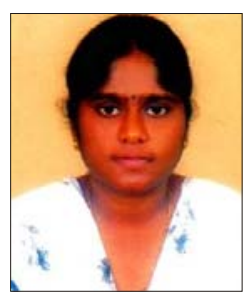

Mohana is a Scientist at the Centre for Remote Sensing and Geo Informatics, Sathyabama University. She has published six papers in International Conferences and one paper in International Journal. 